[Chem. Pharm. Bull.

[35( 9$) 3888-3893(1987)]$

\title{
Pharmacological Activities of Glycyrrhetinic Acid Derivatives: Analgesic and Anti-Type IV Allergic Effects
}

\author{
Hideo Inoue, ${ }^{*, a}$ Takeo Mori, ${ }^{a}$ Shoji Shibata, ${ }^{b}$ \\ and Hiroshi SAITO ${ }^{c}$ \\ Research Laboratory, Minophagen Pharmaceutical Co., ${ }^{a}$ 2-5233, Komatsubara, Zama-shi, \\ Kanagawa 228, Japan, Laboratory of Natural Medicinal Materials, Minophagen \\ Pharmaceutical Co., ${ }^{b}$ 3-2-7, Yotsuya, Shinjuku-ku, Tokyo 160, Japan \\ and Department of Chemical Pharmacology, Faculty of \\ Pharmaceutical Sciences, University of Tokyo, ${ }^{c}$ \\ Hongo, Bunkyo-ku, Tokyo 113, Japan
}

(Received February 3, 1987)

\begin{abstract}
Glycyrrhetinic acid (Ia) and fourteen derivatives of glycyrrhetinic acid were examined to estimate the antinociceptive activity (tests on writhing and vascular permeability induced by $0.7 \%$ acetic acid) and anti-type IV allergic effects in mice. Among them, three dihemiphthalate compounds (IIf, IIIc, IVc) derived from, deoxoglycyrrhetol (IIa), showed strong inhibition of writhing and dye leakage at a dose of $6.25 \mathrm{mg} / \mathrm{kg}$ (p.o.) and type IV allergy at $25 \mathrm{mg} / \mathrm{kg}$ (i.p.). Among the hemisuccinate compounds, Ib, IIb and IIIb, had significant inhibitory effects on both writhing and vascular permeability, whereas IIc and IVb inhibited only one of the two responses, at $200 \mathrm{mg} / \mathrm{kg}$ (p.o.). Four of the hemisuccinate compounds (IIb, c, IIIb, IVb) suppressed type IV allergy at $100 \mathrm{mg} / \mathrm{kg}$ (i.p.). Glycyrrhetinic acid (Ia) and deoxoglycyrrhetol (IIa) showed no detectable inhibition in the screening tests at doses of less than $200 \mathrm{mg} / \mathrm{kg}$ (i.p.).
\end{abstract}

Keywords - glycyrrhetinic acid; antinociceptive activity; type IV allergy; dihemiphthalate compound; hemisuccinate compound; deoxoglycyrrhetol; oleanane skeleton

\section{Introduction}

Glycyrrhetinic acid (Ia), the aglycone of glycyrrhizin, which is obtained from the root of licorice (Glycyrrhiza spp.), is an effective anti-inflammatory agent. ${ }^{1)}$ Nishino et al. ${ }^{2)}$ found an inhibitory effect of glycyrrhetinic acid on tumor-promoting activity. Glycyrrhetinic acid has recently been shown to be an inhibitor of intercellular junctional communication. ${ }^{3)}$ Carbenoxolone sodium (Ib) prepared from glycyrrhetinic acid, is clinically employed in the therapy of gastric ulcer. ${ }^{4)}$ A glycyrrhetinic acid derivative, the sodium salt of glycyrrhetinic acid hemiphthalate (Ic), was demonstrated to have an anti-inflammatory effect. ${ }^{5)}$ It has also been reported that deoxoglycyrrhetol (IIa) inhibits experimental gastric ulcer and allergy. ${ }^{6}$ Furthermore, three dihemiphthalate compounds (the disodium salts of $18 \beta$-olean-12-ene$3 \beta, 30$-diol $3 \beta, 30$-di- $O$-hemiphthalate (IIf), $18 \beta$-olean-9(11),12-diene-3 $\beta, 30$-diol $3 \beta, 30$-di- $O$ -

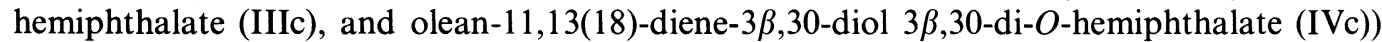
have been shown to prevent gastric ulcer. ${ }^{7)}$ Previously we reported that among fifteen derivatives of glycrrhetinic acid so far tested, the dihemiphthalate compounds (IIf, IIIc and IVc) showed strong inhibitory effects on the 5- and 12-lipoxygenase and cyclooxygenase activities in cloned mastocytoma. ${ }^{8)}$

The present paper describes a further pharmacological study on these compounds in order to examine whether some of them are effective in the writhing and type IV allergy tests. 


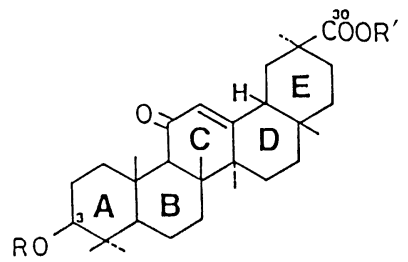

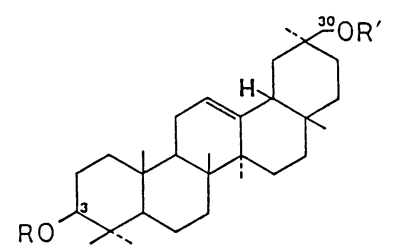

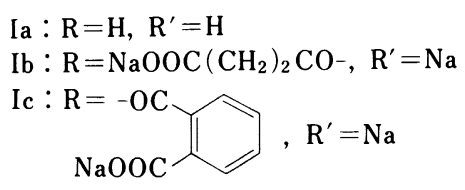

IIa : R=H, $\mathrm{R}^{\prime}=\mathrm{H}$

IIb : $\mathrm{R}=\mathrm{NaOOC}\left(\mathrm{CH}_{2}\right)_{2} \mathrm{CO}-, \mathrm{R}^{\prime}=\mathrm{H}$

IIe $: \mathrm{R}=-\mathrm{OC}$

IIc : $\mathrm{R}=\mathrm{NaOOC}\left(\mathrm{CH}_{2}\right)_{2} \mathrm{CO}$, $\mathrm{R}^{\prime}=\mathrm{NaOOC}\left(\mathrm{CH}_{2}\right)_{2} \mathrm{CO}^{-}$

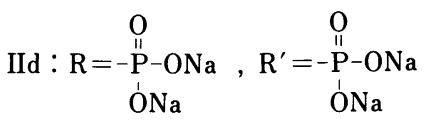<smiles>CCO[Ru]=[Al]</smiles><smiles>[R]OC(=O)c1cccc(NOC(=O)c2ccccc2O[R])c1C(=O)O[R]</smiles>
ONa $\quad$ ONa

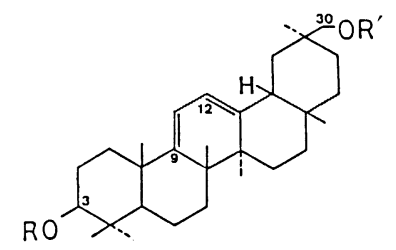

IIIa : $\mathrm{R}=\mathrm{H}, \mathrm{R}^{\prime}=\mathrm{H}$

IIIb : $\mathrm{R}=\mathrm{NaOOC}\left(\mathrm{CH}_{2}\right)_{2} \mathrm{CO}-, \mathrm{R}^{\prime}=\mathrm{H}$

III $\mathrm{c}: \mathrm{R}=-\mathrm{OC}$

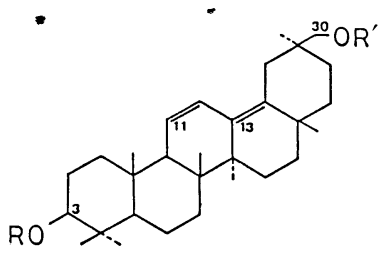

IVa: $\mathrm{R}=\mathrm{H}, \mathrm{R}^{\prime}=\mathrm{H}$
$\mathrm{IVb}: \mathrm{R}=\mathrm{NaOOC}\left(\mathrm{CH}_{2}\right)_{2} \mathrm{CO}-, \mathrm{R}^{\prime}=\mathrm{H}$
$\mathrm{IVc}: \mathrm{R}=-\mathrm{OC}$

Chart 1

\section{Materials and Methods}

Animals — Male ddY mice (6-7 weeks old) used in this experiment were purchased from the Shizuoka Laboratory Animal Center (Shizuoka, Japan). Animals were housed in an air-conditioned room at $22 \pm 1^{\circ} \mathrm{C}$ with $55 \pm 5 \%$ relative humidity, and were given free access to food and water. They were used after taming for 1 week.

Test Compounds - Glycyrrhetinic acid, its derivatives and phthalic acid were prepared by Mr. N. Nagata, Minophagen Research Laboratory. Aminopyrine (Sigma Chemical Co., U.S.A.) for the writhing tests and prednisolone (Shionogi Pharmaceutical Co., Japan) for type IV allergy were used as positive controls.

Assay for Analgesic Activity-Analgesic effects of the compounds were estimated in terms of the effects on writhing and vascular prermeability induced by acetic acid. The test compounds were dissolved in physical saline containing $1 \%$ Tween 80 and given orally $45 \mathrm{~min}$ prior to the intraperitoneal injection $(10 \mathrm{ml} / \mathrm{kg})$ of $0.7 \%$ acetic acid solution; $0.1 \mathrm{ml} /$ animal of $4 \%$ Evans blue was also intravenously given at $10 \mathrm{~min}$ before the administration of acetic acid. The number of writhes of each mouse was counted during a period of $20 \mathrm{~min}$ after the acetic acid injection. For the examination of vascular permeability, the mice used in the writhing tests were immediately sacrificed and injected with $3 \mathrm{ml}$ of saline intraperitoneally. The fluid collected from the peritoneal cavity was added to $2 \mathrm{ml}$ of saline and centrifuged at $3000 \mathrm{rpm}$ for $10 \mathrm{~min}$. The dye in the supernatant was measured spectrophotometrically at $590 \mathrm{~nm}$. The results were expressed as inhibition (percent) of writhing and dye-leakage in the test groups as compared with the control.

Assay for Anti-Allergic Activity - The anti-allergic effect of the compounds was examined on picryl chloride (PC)-induced type IV allergy in the ear of mice. Sensitization of mice was performed according to the method of Asherson and Ptak. ${ }^{9)}$ Firstly, the abdomen of mice (shaved prior to the experiment) was treated with $100 \mu 1$ of $7 \%$ PC-ethanol solution. Seven days after PC-treatment, the animals were challenged with $20 \mu \mathrm{l} /$ ear of antigen ( $1 \%$ PColive oil) on both ears, and after further $5 \mathrm{~d}$, these sensitization were repeated. The test compounds, dissolved in physical saline containing $1 \%$ Tween 80 , were intraperitoneally injected into mice at 0,3 and $9 \mathrm{~h}$ after the second challenge. The ear thickness was measured with a dial thickness guage (Ozaki Factory, Japan) with the unit of $0.01 \mathrm{~mm}$ at 9 and $24 \mathrm{~h}$ after the second challenge. The results were expressed as the inhibition (percent) of swelling relative to the control, after subtracting the thickness before challenge.

Data Analysis - Student's $t$-test was used to determine statistical significance. 


\section{Results and Discussion}

\section{Effects of Glycyrrhetinic Acid Derivatives on Writhing and Vascular Permeability}

The effects of the compounds tested on the acetic acid-induced writhing and vascular permeability are summarized in Table I. In the control groups, the number of writhes was $26.7 \pm 1.4$ (S.E.) while the OD value of peritoneal dye-leakage was $0.403 \pm 0.03$ (S.E.) under our experimental conditions. Some of the test compounds inhibited both writhing and vascular permeability. Three hemiphthalate compounds [the disodium salts of $18 \beta$-olean-12ene-3 $\beta, 30$-diol $3 \beta, 30$-di- $O$-hemiphthalate (IIf), $18 \beta$-olean-9(11), 12-diene-3 $\beta, 30$-diol $3 \beta, 30$-di$O$-hemiphthalate (IIIc) and olean-11,13(18)-diene-3 $\beta, 30$-diol 3 $\beta, 30$-di- $O$-hemiphthalate (IVc)] exhibited the strongest inhibition of writhing and vascular permeability, and showed significant effects at a dose of $6.25 \mathrm{mg} / \mathrm{kg}$ (p.o.). The hemisuccinate compounds (IIb, c and

TABLE I. Inhibition of Acetic Acid-Induced Writhing and Vascular Permeability by Glycyrrhetinic Acid Derivatives

\begin{tabular}{|c|c|c|c|}
\hline Compound & $\begin{array}{c}\text { Dose } \\
(\dot{\mathrm{m} g} / \mathrm{kg})(\text { p.o. })\end{array}$ & Writhing & Dye-leakage \\
\hline Ia & 200 & 13 & 13 \\
\hline \multirow[t]{2}{*}{$\mathrm{Ib}$} & 100 & 3 & 28 \\
\hline & 200 & $58^{a)}$ & $43^{b)}$ \\
\hline \multirow[t]{2}{*}{ Ic } & 100 & 15 & 14 \\
\hline & 200 & 18 & 0 \\
\hline \multirow[t]{2}{*}{ IIa } & 100 & 21 & 11 \\
\hline & 200 & 24 & 22 \\
\hline \multirow[t]{2}{*}{ IIb } & 100 & 0 & 7 \\
\hline & 200 & $66^{a)}$ & $32^{b)}$ \\
\hline \multirow[t]{2}{*}{ IIc } & 100 & 7 & 23 \\
\hline & 200 & $45^{b)}$ & 26 \\
\hline \multirow[t]{2}{*}{ IId } & 100 & 0 & 28 \\
\hline & 200 & 28 & $29^{b)}$ \\
\hline \multirow[t]{2}{*}{ IIe } & 100 & 18 & 18 \\
\hline & 200 & 36 & $38^{b)}$ \\
\hline \multirow[t]{4}{*}{ IIf } & 3.13 & 20 & 19 \\
\hline & 6.25 & $32^{b)}$ & $34^{b)}$ \\
\hline & 12.5 & $29^{b)}$ & $58^{a)}$ \\
\hline & $25^{*}$ & $43^{b)}$ & $55^{a)}$ \\
\hline IIIa & 200 & 13 & 11 \\
\hline \multirow[t]{2}{*}{ IIIb } & 100 & 22 & 25 \\
\hline & 200 & $40^{b)}$ & $37^{b)}$ \\
\hline \multirow[t]{4}{*}{ IIIc } & 3.13 & 21 & 9 \\
\hline & 6.25 & $45^{b)}$ & $50^{b)}$ \\
\hline & 12.5 & $37^{b)}$ & $39^{b)}$ \\
\hline & 25 & $64^{b)}$ & $55^{a)}$ \\
\hline IVa & 200 & 29 & 19 \\
\hline \multirow[t]{2}{*}{$\mathrm{IVb}$} & 100 & 6 & 0 \\
\hline & 200 & 35 & $39^{b)}$ \\
\hline \multirow{4}{*}{ IVc } & 3.13 & 22 & 17 \\
\hline & 6.25 & $46^{b)}$ & $59^{b)}$ \\
\hline & 12.5 & $71^{a)}$ & $48^{a)}$ \\
\hline & 25 & $63^{a)}$ & $49^{a)}$ \\
\hline Phthalic acid & 200 & 16 & 0 \\
\hline Aminopyrine & 200 & $100^{c)}$ & $70^{a)}$ \\
\hline
\end{tabular}

Values of inhibition are expressed as percent of the control $(n=7-8) . a) p<0.01 ; b) p<0.05 ; c)$ $p<0.001$. 
IIIb) including carbenoxolone sodium (Ib), which have a sodium succinate group at position 3 or 30 in the oleanane skeleton, showed activity at $200 \mathrm{mg} / \mathrm{kg}$ (p.o.), but a dose of less than $100 \mathrm{mg} / \mathrm{kg}$ (p.o.) exhibited no apparent inhibition. In contrast, glycyrrhetinic acid (Ia), deoxoglycyrrhetol (IIa), 18 $\beta$-olean-9(11), 12-diene-(IIIa) and 18 $\beta$-olean-11,13(18)-diene-3 $\beta, 30$-diol (IVa), the skeletal compounds of the above derivatives, were found to have weak inhibitory effects on the writhing response. The compounds having sodium hemiphthalate groups at the 3- and 30-positions of rings $\mathrm{A}$ and $\mathrm{E}$ in the oleanane skeleton (IIf, IIIc and IVc) showed potent inhibition. The monosodium salt of $18 \beta$-olean-12-ene-3 $\beta, 30$-diol $3 \beta$ - $O$-hemiphthalate (IIe) showed a slight effect, but it was not statistically significant. Compound Ic was less effective in inhibiting writhing than glycyrretinic acid (Ia). In addition, we confirmed that phthalic acid itself did not affect writhing or vascular permeability induced by acetic acid. These results suggest that dihemiphthalate substitution on the oleanane skeleton is required for a potent inhibitory effect on writhing and vascular permeability.

\section{Effect of Glycyrrhetinic Acid Derivatives on Type IV Allergy}

A primary screening of glycyrrhetinic acid derivatives was performed for inhibitory effect on PC-induced type IV allergy (Table II). The compounds tested were given intraperitoneally immediately after the second challenge. Each value was expressed as inhibition (percent) of ear swelling at $9 \mathrm{~h}$ after challenge. Some compounds (Ib, c, IIe, f, IIIc and IVc) were administered at less than $50 \mathrm{mg} / \mathrm{kg}$ since their $\mathrm{LD}_{50}$ (i.p.) values were 60 to $150 \mathrm{mg} / \mathrm{kg}$. As shown in Table II, three dihemiphthalates (IIf, IIIc and IVc) and four hemisuccinates (IIb, c, IIIb and IVb), showed significant inhibition of type IV allergy at 25 to $100 \mathrm{mg} / \mathrm{kg}$. Another hemisuccinate compound, carbenoxolone sodium (Ib), was also found to have inhibitory activity, but Ia, IIa, IIIa and IVa did not have significant effects. The inhibitory effects of the seven derivatives (IIb, c, f, IIIb, c, IVb, c) were further investigated (Table III). These compounds showed potent inhibitory activity, suppressing about $60 \%$ of ear swelling when

TABLE II. Inhibition of PC-Induced Contact Dermatitis by Glycyrrhetinic Acid Derivatives

\begin{tabular}{|c|c|c|c|c|c|}
\hline Compound & $\begin{array}{c}\text { Dose } \\
(\mathrm{mg} / \mathrm{kg})\end{array}$ & $\begin{array}{c}\text { Inhibition } \\
(\%)\end{array}$ & Compound & $\begin{array}{c}\text { Dose } \\
(\mathrm{mg} / \mathrm{kg})\end{array}$ & $\begin{array}{c}\text { Inhibition } \\
(\%)\end{array}$ \\
\hline \multirow[t]{2}{*}{ Ia } & 100 & 15 & IIIa & 200 & 6 \\
\hline & 200 & 35 & IIIb & 50 & 18 \\
\hline \multirow[t]{2}{*}{$\mathrm{Ib}$} & 25 & 14 & & 100 & $32^{a)}$ \\
\hline & 50 & $22^{a)}$ & & 200 & $43^{b)}$ \\
\hline Ic & 50 & 0 & IIIc & 12.5 & 4 \\
\hline \multirow[t]{2}{*}{ IIa } & 100 & 15 & & 25 & $42^{a)}$ \\
\hline & 200 & 18 & IVa & 100 & 21 \\
\hline \multirow[t]{3}{*}{ IIb } & 50 & 0 & & 200 & 0 \\
\hline & 100 & $23^{a)}$ & $\mathrm{IVb}$ & 50 & 0 \\
\hline & 200 & $33^{b)}$ & & 100 & $44^{a)}$ \\
\hline \multirow[t]{3}{*}{ IIc } & 50 & 0 & & 200 & $43^{b)}$ \\
\hline & 100 & $55^{b)}$ & IVc & 12.5 & 20 \\
\hline & 200 & $76^{b)}$ & & 25 & $45^{b)}$ \\
\hline \multirow[t]{2}{*}{ IId } & 100 & 17 & Prednisolone & 5 & $42^{b)}$ \\
\hline & 200 & $52^{b)}$ & & 10 & $77^{c)}$ \\
\hline IIe & 25 & 16 & & & \\
\hline \multirow[t]{2}{*}{ IIf } & 12.5 & 13 & & & \\
\hline & 25 & $19^{a)}$ & & & \\
\hline
\end{tabular}

Values of inhibition are expressed as percent of the control at $9 \mathrm{~h}$ after challenge $(n=7-8)$. Compounds were given i.p. immediately after challenge. a) $p<0.05 ; b) p<0.01 ; c) p<0.001$. 
TABLE III. Inhibition of PC-Induced Contact Dermatitis by Seven Derivatives of Glycyrrhetinic Acid

\begin{tabular}{ccll}
\hline \hline & & Inhibition $(\%)$ after challenge \\
\cline { 2 - 4 } Compound & $\begin{array}{c}\text { Dose } \\
\text { (mg/kg) }\end{array}$ & $9 \mathrm{~h}$ & $24 \mathrm{~h}$ \\
\hline \multirow{2}{*}{ IIb } & 100 & 33 & 36 \\
& 200 & $57^{a)}$ & $54^{b)}$ \\
IIc & 50 & 16 & 34 \\
& 100 & $58^{a)}$ & $69^{a)}$ \\
IIf & 200 & 53 & $85^{b)}$ \\
& 12.5 & 23 & 22 \\
IIIb & 25 & $59^{b)}$ & $66^{b)}$ \\
& 100 & 44 & 35 \\
IIIc & 200 & $58^{b)}$ & $70^{b)}$ \\
& 12.5 & 41 & 28 \\
IVb & 25 & $58^{b)}$ & 25 \\
& 50 & 39 & $64^{b)}$ \\
& 100 & $61^{b)}$ & $74^{b)}$ \\
IVc & 200 & $58^{b)}$ & 23 \\
& 12.5 & 41 & $70^{b)}$ \\
Prednisolone & 25 & $64^{b)}$ & $46^{b)}$ \\
\hline
\end{tabular}

Values of inhibition are expressed as percent of the control $(n=7-8)$. Compounds were given i.p. at 3 and $9 \mathrm{~h}$ after challenge. a) $p<0.05 ; b) p<0.01$.

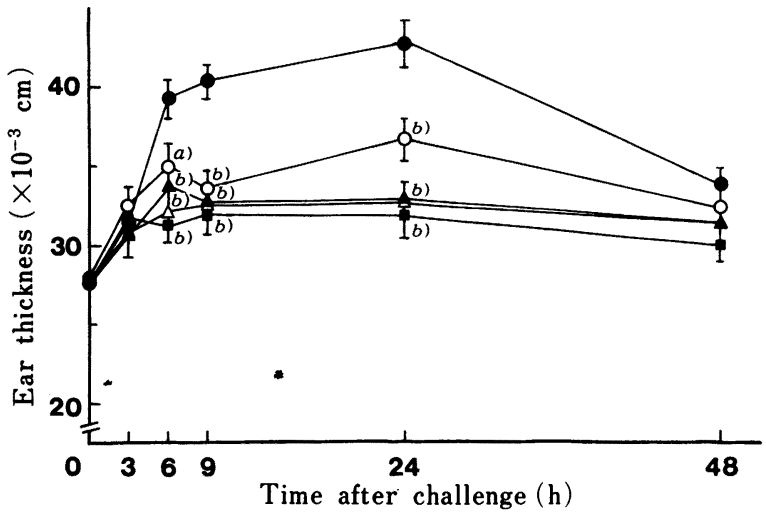

Fig. 1. Inhibitory Effect of Dihemiphthalate Compounds on Type IV Allergy

Each value is the mean + S.E. for 8 animals. Test compounds were given i.p. at 3 and $9 \mathrm{~h}$ after challenge. The assay was carried out as described in Materials and Methods.

$(\bullet)$, saline; $(O)$, prednisolone $5 \mathrm{mg} / \mathrm{kg} ;(\triangle)$, compound IIf $25 \mathrm{mg} / \mathrm{kg} ;(\boldsymbol{\Delta})$, compound

IIIc $25 \mathrm{mg} / \mathrm{kg}$; (ם), compound IVc $25 \mathrm{mg} / \mathrm{kg}$. a) $p<0.05 ; b) p<0.01$.

administered twice at 3 and $9 \mathrm{~h}$ after challenged. In particular, the inhibitory effects at $24 \mathrm{~h}$ after challenge were more potent than those of prednisolone $(5 \mathrm{mg} / \mathrm{kg})$. The dihemiphthalate compounds (IIf, IIIc and IVc) were found to inhibit the ear swelling significantly at $6 \mathrm{~h}$ after challenge (Fig. 1). It is a characteristic of those compounds that the time-course of the ear swelling treated with them was similar to that in the case of prednisolone. However, we do not yet have enough information to discuss the mechanism of inhibitory effect on PC-induced type IV allergy.

We confirmed that some of the glycyrrhetinic acid derivatives inhibited writhing and/or 
peritoneal dye-leakage, as well as type IV allergy. In particular, the dihemiphthalate compounds (IIf, IIIc and IVc) strongly inhibited both writhing and peritoneal leakage, suggesting that these compounds have anti-inflammatory and antinociceptive activity. Previously we found that the dihemiphthalate compounds (IIf, IIIc and IVc) strongly inhibit lipoxygenase and cyclo-oxygenase activities, ${ }^{8)}$ and prevent the formation of gastric ulcer. ${ }^{7)}$ Therefore, these compounds are candidates as drugs to treat inflammation and allergic disease without unfavorable gastric side effects. ${ }^{7)}$

Acknowledgement The authors are greatly indebted to Mr. Nobuyuki Nagata, Research Laboratory, Minophagen Pharmaceutical Co., for the preparation of compounds used in the present study. We also thank Mr. Jun Yagi of this company for his technical suggestions.

\section{References and Notes}

1) R. S. H. Finney and A. L. Tarnoky, J. Pharm. Pharmacol., 12, 49 (1960).,

2) H. Nishino, K. Yoshioka, A. Iwashima, H. Takazawa, S. Konishi, H. Okamoto, S. Shibata, H. Fujiki, and T. Sugimura, Jpn. J. Cancer Res., 77, 33 (1986).

3) J. S. Davidson, J. M. Baumgarten, and E. H. Harley, Biochem. Biophys. Res. Commun., 134, 29 (1986).

4) R. Doll, I. D. Hill, C. Hutton, and D. J. Underwood, Lancet, ii, 2, 793 (1962).

5) S. Tomizawa and Y. Hara, Pharmacometrics, 11, 677 (1976).

6) K. Takahashi, S. Shibata, S. Yano, M. Harada, H. Saito, Y. Tamura, and A. Kumagai, Chem. Pharm. Bull., 28, 3349 (1980); S. Shibata, K. Takahashi, S. Yano, M. Harada, H. Saito, Y. Tamura, A. Kumagai, K. Hirabayashi, M. Yamamoto, and N. Nagata, Chem. Pharm. Bull., 35, 1910 (1987).

7) S. Yano, K. Nakamura, K. Watanabe, M. Harada, K. Takahashi, S. Shibata, N. Nagata, and K. Hirabayashi, Abstracts of Papers, 105th Annual Meeting of Pharmaceutical Society of Japan, Kanazawa, April 1985, p. 155.

8) H. Inoue, H. Saito, Y. Koshihara, and S. Murota, Chem. Pharm. Bull., 34, 897 (1986).

9) G. L. Asherson and W. Ptak, Immunology, 15, 405 (1968). 